\title{
Public Health Innovations Program tailored to Master on Telecommunications' Students
}

\author{
Antonio Martinez-Millana, ${ }^{\mathrm{a}, \mathrm{b}}$, Laura Martinez-Mateu ${ }^{\mathrm{b}}$, Maria S Guillem ${ }^{\mathrm{a}, \mathrm{b}}$, Vicente \\ Traver $^{\text {a,b }}$ \\ ${ }^{a}$ ITACA. Universitat Politècnica de València ${ }^{b}$ Departamento de Ingeniería Electrónica. Universitat \\ Politècnica de València.
}

\begin{abstract}
Developed and under-developed countries are facing several challenges related to public health and sustainability of health care systems. New challenges demand of the collaborative action of multiple stakeholders with different backgrounds. In the late years, telecommunication engineers are involved in a wide range of companies and institutions to help designing and building innovative and efficient solutions, among which public health is a paradigmatic example. In this paper authors introduce a program for teaching public health principles and tools focused at telecommunications master students. The program is presented in five practices of three hours duration (fifteen hours overall). The sessions are structured in the classic problem-solving methodology in which the students must respond to concrete and general questions by the application of knowledge, practice and reasoning. Each practice includes theoretical framework introduction, provision of tools and use of open repositories to complete the assignments. The covered topics are: mobile health and usability, open data, data mining, Internet of Things and wearable and process mining.
\end{abstract}

Keywords: ICT, Public Health, Innovation, Telecommunications.

\section{Introduction}

The burden of chronic conditions and the dramatic ageing of populations are challenging factors for the sustainability of healthcare systems (Majumder, Mondal, \& Deen, 2017). The economic and financial crisis of 2008 has pushed scientist, healthcare managers, policy makers and economists to propose new ways of organizing the delivery of care and improving efficiency(WHO, 2009). Among the novel proposed changes, the use of new medical technologies based on molecular therapies, new devices and information systems 
have gained attention in the last few years and nowadays there are paradigmatic solutions scaling up (Monton et al., 2018).

Advances in sensing technologies and the democratization of internet access has allowed research centers to propose decentralized systems for the acquisition, transmission and processing of health-related information with the aim of improving the healthcare quality and efficiency. In this paper we present a teaching framework based on five practical sessions to introduce telecommunications students into the basic concepts of innovations in public health systems.

\section{Program}

The subject Applications of Information Technologies in the Health Sector contributes to provide students with skills to put into practice the knowledge acquired throughout the Telecommunications bachelor degree (and other technical degrees) in the field of public health. In addition, it provides students with an engineering vision that goes beyond the purely technological expertise to identify, analyze and solve problems in any Information and Communications Technologies (ICT) health related system (Martinez-millana, Fernandez-llatas, \& Traver, 2016). Thus, the objectives of the course are: a) To provide students with theoretical knowledge and practical skills in the technologies necessary for the specification, design, development, deployment and evaluation of e-health systems b) Convey to students the need for telemedicine and e-health in the health and socioeconomic context of our society. c) To train students to analyze e-health systems from different perspectives: social, economic, technical and d) To train students to be able to finish the course of proposing an e-health system considering the phases of design, specification, development, implementation and evaluation.

The theory program includes twelve lectures on several topics, including usability, research methods, big data, internet of things, mobile health, sensors, policy framework and social media. Each lecture includes basic contents and references so students can have a general idea of the proposed technology/method and know its advantages and limitations to design eHealth systems. The theory program is complemented with five practical sessions in the laboratory, which requires special software and hardware, and helps students to put into practice the knowledge worked in the theory sessions and the work at home. The following subsections describe the proposed program for each practical session 


\subsection{Practice 1: Mobile Health}

Mobile Medical Apps Certification. This practice consists of two independent exercises, based on the theory on Lecture 1 and Lecture 2. The major objectives of the hands on session are to provide the students with the skills for: Differentiation of what is and what is not a mobile medical application; Use existing marketplaces and repositories to search and compare mobile health applications; Meet regulations and features of medical mobile application.

Table 1. Example of the App repository for practice 1 . Font: self elaboration

\begin{tabular}{|c|c|c|c|c|c|}
\hline NAME & $\begin{array}{c}\text { CLASS TYPE } \\
\text { (FDA } \\
\text { classification) }\end{array}$ & PROMOTER & $\begin{array}{c}\text { TYPE OF } \\
\text { PROMOTER }\end{array}$ & DOWNLOADS & REVIEWS \\
\hline Huawei Health & Type B.6 & $\begin{array}{c}\text { Huawei Internet } \\
\text { Service }\end{array}$ & $\begin{array}{c}\text { Mobile } \\
\text { Manufacturer }\end{array}$ & $100,000,000+$ & $\begin{array}{c}120,635 \\
(3,7)\end{array}$ \\
\hline $\begin{array}{l}\text { Calorie Counter } \\
\text { - MyFitnessPal }\end{array}$ & Type B.6 & $\begin{array}{l}\text { MyFitnessPal, } \\
\text { Inc. }\end{array}$ & App Developer & $50,000,000+$ & $\begin{array}{c}2,158,397 \\
(4,5)\end{array}$ \\
\hline $\begin{array}{l}\text { Health and } \\
\text { Fitness } \\
\text { Calculators }\end{array}$ & Type B.2 & Bitapp & App Developer & $1,000+$ & $19(4,2)$ \\
\hline Health Tracker & Type B.2 & $\begin{array}{l}\text { Cool Apps } \\
\text { Creation }\end{array}$ & App Developer & $100,000+$ & $253(3,5)$ \\
\hline $\begin{array}{c}\text { Sanitas } \\
\text { HealthCoach }\end{array}$ & $\begin{array}{c}\text { Type } \\
\text { AppendixA.2 }\end{array}$ & $\begin{array}{c}\text { Hans Dinslage } \\
\text { GmbH }\end{array}$ & $\begin{array}{l}\text { Wellness and } \\
\text { Health } \\
\text { Manufacturer }\end{array}$ & $500,000+$ & $22,592(2,9)$ \\
\hline Men's Health & Type A.3 & $\begin{array}{c}\text { Prof. Osama } \\
\text { Shaeer }\end{array}$ & $\begin{array}{c}\text { App Developer } \\
\text { (Person) }\end{array}$ & $5,000+$ & $60(4,5)$ \\
\hline
\end{tabular}

The definition and legal framework of a medical device depends on the market and geographic area. In the European Union, the 2007/47/EC directive provides the aforementioned definition, but delegates to the corresponding office for each Member State the responsibility of transposing of medical device directives into national law to apply them. In the Unites States, the Food and Drug Administration is the regulatory body in charge of defining laws, procedures and penalties for Medical Devices, defining them as any medical machine, implant, other similar or related article or component intended for use in the diagnosis of disease or other conditions, or in the cure, mitigation, treatment, or prevention of disease, in man or other animals. 
In the first part of the practice students have to build their own repository of mobile medical applications for a specific context (e.g.: diabetes, dermatology, cardiology, pediatrics, cancer, mental health, etc..). Existing marketplaces and databases should be used with specific search constraints to retrieve apps and store descriptors (name, manufacturer, intended users, last update, rating, number of downloads and description). Based on current guidelines, students have to classify the medical app according to the description of the FDA guidelines (Appendix A or Appendix B) or not a medical device (Table 1).

\subsection{Practice 1: Open Data}

In this practical session students work with Open Data tools to analyze Public Health data. Openness or transparency is a traditional good governance principle. Back from 18th Century, the freedom of information right has been established in many Western countries and these last years, Governments around the world are defining and implementing Open Data strategies in order to increase transparency, participation and/or government efficiency. The commonly accepted premise underlying these strategies is to publishing government data in a reusableformat to strengthen citizen engagement and yield new innovative businesses.

In the practice students have to go to the portal on mortality rates in Valencian Region, which contains information on the mortality in each municipality of the Valencian Community on the basis of different diseases from 1987 to 2006 (Figure 1). Students have to observe different diseases and analyze the prevalence and incidence for given regions, genders and time intervals. Students have to interpret these open data and make their own assessments: "In 1987 the main regions of risk were the provinces Valencia and Alicante, and the lower ones were the smallest towns (La Nucia, Alfaz del Pi, Benitachell, etc). This is due to the population and the development of these cities, as this disease is seen as typical of high-income classes". 

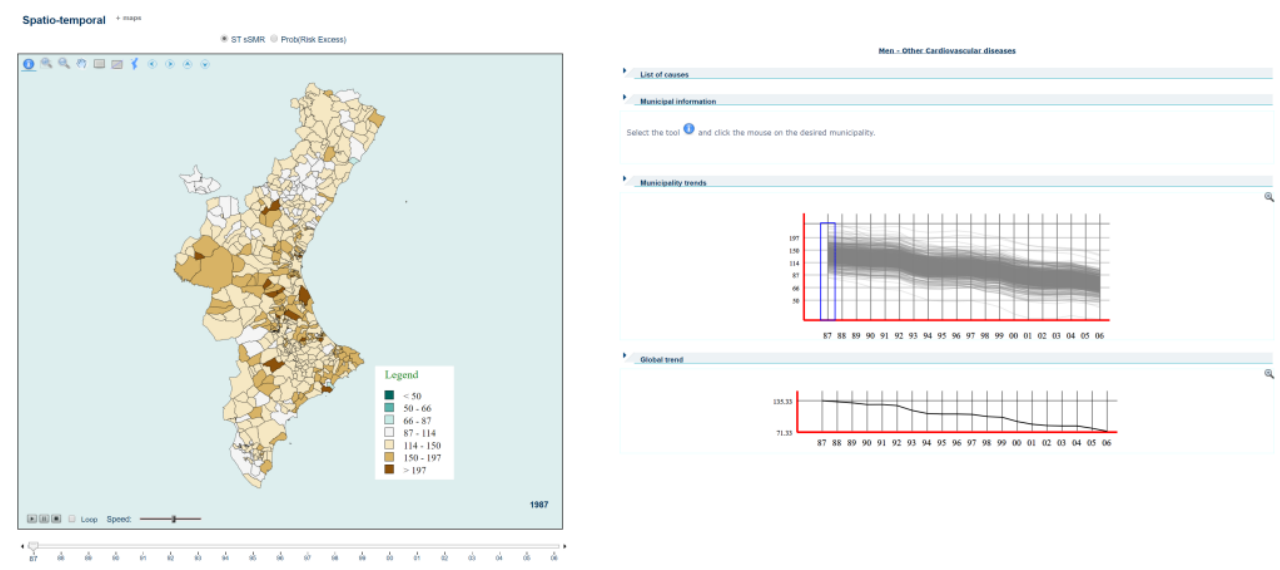

Fig. 1 Example of the analysis for cardiovascular diseases by regions and time intervals. Font: web site of Public Health Open Data service of the Valencian Health Region.

\subsection{Practice 3: Open hardware Arduino}

In this practical session students work with Arduino, an open source platform based on a connection board with the minimum capacity to execute simple programs (sketch). Arduino has succeeded on their approach of creating an easy but effective hardware which is able to connect and use many electronic components with a several range of applications. Arduino provides an excellent platform to test and prototype solutions by adding supplemental modules (Bluetooth, WiFi boards, LEDs, servo-motors) and other hardware solutions. In this practice we are going to use the eHealth Biometric Sensor Platform created by Libelium. This kit allows to acquire a set of physiological signals such as: Electro Cardio Graphy (ECG), Electro Miogra Graphy (EMG), breathing rate, Surface temperature, Galvanic Skin Response, blood glucose, $\mathrm{SpO} 2$.

Students have to configure the software and the hardware and retrieve signals from the biometric platform. Some questions are posed to understand the basic functioning of the sensors and the programming interface to manage the data.

\subsection{Practice 4: Signal processing}

In this practice students have to analyse temporal series signal acquired with the ECG sensors of the Arduino eHealth kit. ECG signal is a result of recording the electrical activity of the heart over a period of time using electrodes placed on the skin. Electrodes may be positioned over leads. A lead is a standard vector (or source of signal) used to acquire electrical signal. Leads are broken down into three sets: limb, augmented limb, and 
precordial. In this practice we use a vector containing measurements from the limb leads, specifically Lead I. Lead I is the voltage between the (positive) left arm (LA) electrode and right arm (RA) electrode. This lead I signal contains the main waves in a standard ECG recording $(\mathrm{P}, \mathrm{Q}, \mathrm{R}, \mathrm{S}, \mathrm{T})$, in which the time between consecutive $\mathrm{R}$ peaks is known as the RR interval.

Students have to acquire the ECG signal in a Matlab (Mathworks Inc) program and implement a processing pipeline with the stages shown in Figure 2. The proposed analysis is based on the temporal domain, but students can choose to do the analysis in the frequency domain by applying the Fast Fourier Transformation (FFT).

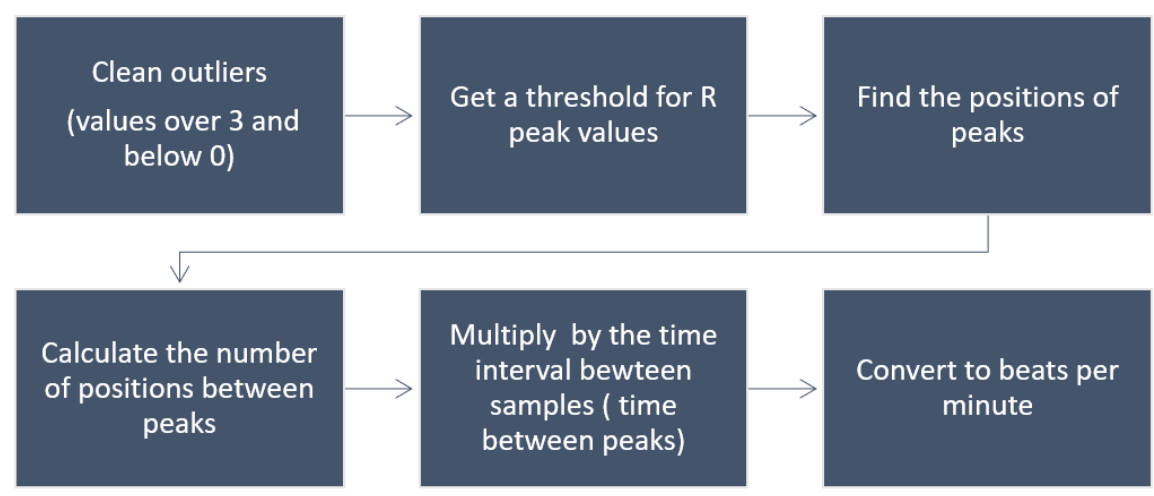

Fig. 2 Workflow for the pre-processing and analysis of ECG signal to calculate the Beats Per Minute.

Font: self elaboration

\subsection{Practice 4: Process mining}

Process mining is a technique that focuses on extracting knowledge from data stored in the form of events (Action + time stamp) which has the objective of providing insights on the process that produced that data. Improving health care processes is not an easy task, even though it is clear that by its optimization, patient's quality of life and use of clinical resources can be increased and optimized. In this practice students reinforce the concept of process mining (a topic introduced in the theory lecture), by using a custom made framework (PALIA) and a real dataset of Outpatient Clinics (Figure 3).

Among the proposed exercises, students have to load a log of events containing visits to the outpatient clinics of a major hospital (anonymized and dissociated records) and discover the processes that patients perform when visiting the hospital. Some patients come before the scheduled time, and other come after the scheduled time. The tool enables to study the waiting times and its variation according to the time interval of the day (early morning, 
afternoon), the type of clinical service and the number of appointments the patient has scheduled.

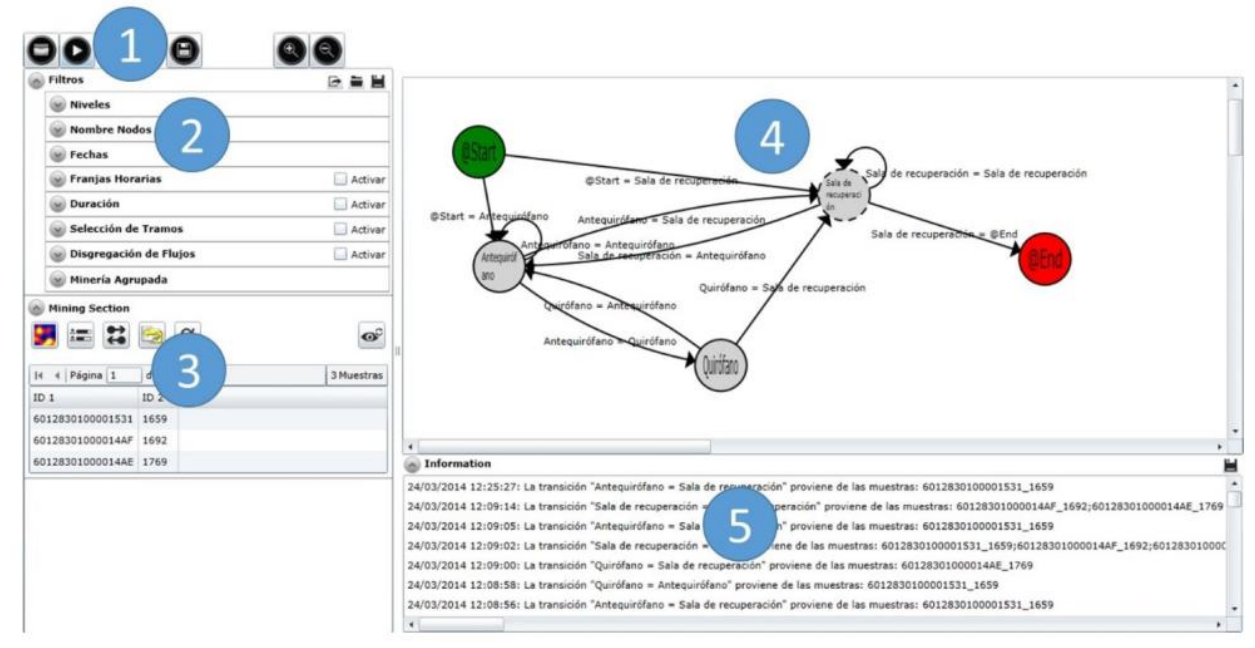

Fig. 3 Example of the PALIA framework for the process mining analytics.

Font: PALIA web

\section{Conclusion}

This paper summarizes a practical program for acquiring and putting in practice knowledge related to health innovations for public health oriented to telecommunication students at master level. The program includes five practical sessions in which students can develop skills to analyze open data, analyze mobile health apps, work with hardware and signal processing and reinforce process mining abilities.

Current challenges in public health demand new visions and skills for posing solutions based on technologies and organizational innovation. This educational program may be used for expanding these skills in other technical degrees, such as biomedical engineering and computer science. 
Title comu Public Health Innovations Program tailored to Master on Telecommunications' Studentsnication

Table 2. learning outcomes and matching with the practices of the program (self elaboration)

\begin{tabular}{|l|l|l|l|l|l|}
\hline & $\begin{array}{l}\text { Usability } \\
\text { assessment } \\
\text { tools } \\
\text { knowledge }\end{array}$ & $\begin{array}{l}\text { Advanced } \\
\text { signal } \\
\text { processing } \\
\text { ability }\end{array}$ & $\begin{array}{l}\text { Programming } \\
\text { ability }\end{array}$ & $\begin{array}{l}\text { Process } \\
\text { Mining } \\
\text { knowledge }\end{array}$ & $\begin{array}{l}\text { Ability to apply } \\
\text { lessons learned } \\
\text { in another } \\
\text { context }\end{array}$ \\
\hline $\begin{array}{l}\text { Practice 1: } \\
\text { Mobile Health }\end{array}$ & $\mathrm{x}$ & $\mathrm{x}$ & $\mathrm{x}$ & & \\
\hline $\begin{array}{l}\text { Practice 2: Open } \\
\text { Data }\end{array}$ & & $\mathrm{x}$ & & \\
\hline $\begin{array}{l}\text { Practice 3: Open } \\
\text { Hardware/Ardui } \\
\text { no }\end{array}$ & & $\mathrm{x}$ & $\mathrm{x}$ & & \\
\hline $\begin{array}{l}\text { Practice 4: } \\
\text { Signal } \\
\text { processing }\end{array}$ & & & & $\mathrm{x}$ & \\
\hline $\begin{array}{l}\text { Practice } \\
\text { Process Mining }\end{array}$ & & & & & \\
\hline
\end{tabular}

\section{References}

Majumder, S., Mondal, T., \& Deen, M. J. (2017). Wearable Sensors for Remote Health Monitoring. Sensors (Basel, Switzerland), 17(1). https://doi.org/10.3390/s17010130

Martinez-millana, A., Fernandez-llatas, C., \& Traver, V. (2016). eHealth Perceptions of Biomedical Engineering Students. (May).

Monton, J. L. B., Martinez-Millana, A., Han, W., Fernandez-Llatas, C., Sun, Y., \& Traver, V. (2018). Wearable sensors integrated with internet of things for advancing ehealth care. Sensors (Switzerland), 18(6), 1-18. https://doi.org/10.3390/s18061851

WHO. (2009). Global Health Risks. Who, 9-27. Retrieved from http://www.who.int/healthinfo/global_burden_disease/GlobalHealthRisks_report_part2.pdf 